\title{
Landesverband Saarland, Regionalgruppe Oldenburg
}

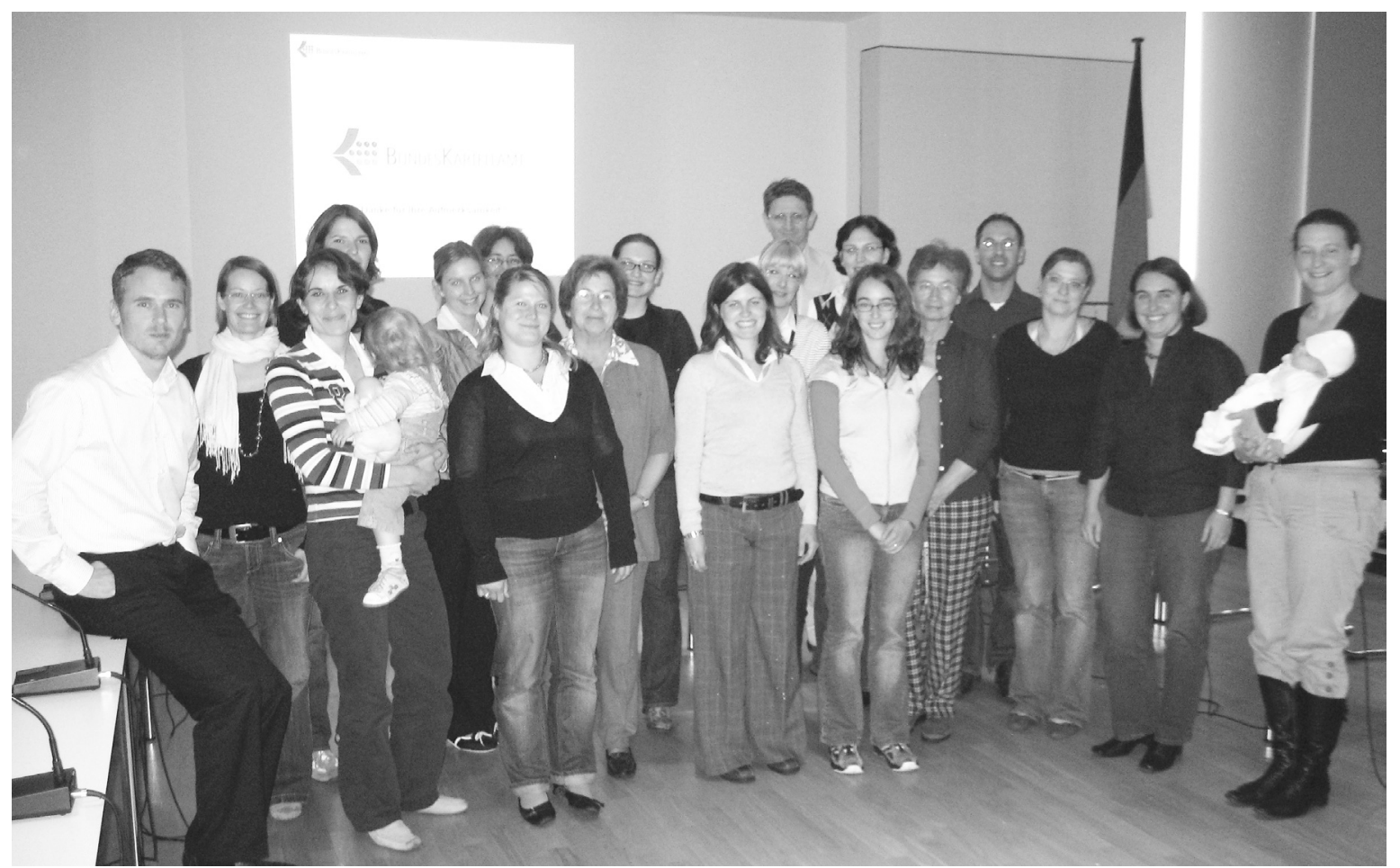

$\Delta$ Der Landesverband Saarland organisierte für den 13. Juni 2008 eine Zugfahrt nach Bonn mit einem Vortrag im Bundeskartellamt und einer anschließenden Führung im Haus der Geschichte. Am Haus der Geschichte beginnt auch der „Weg der Demokratie“, dem die Teilnehmerinnen und Teilnehmer dann folgten. Der Rundgang besteht aus beschilderten Stationen an zeithistorischen Orten im ehemaligen Regierungsviertel in Bonn. Im Bild: Mitglieder des Landesverbands Saarland, ein Mitglied der RG Trier mit Familie und (ganz links) der Referent aus dem Referat für Öffentlichkeitsarbeit des Bundeskartellamts, Markus Zeise.

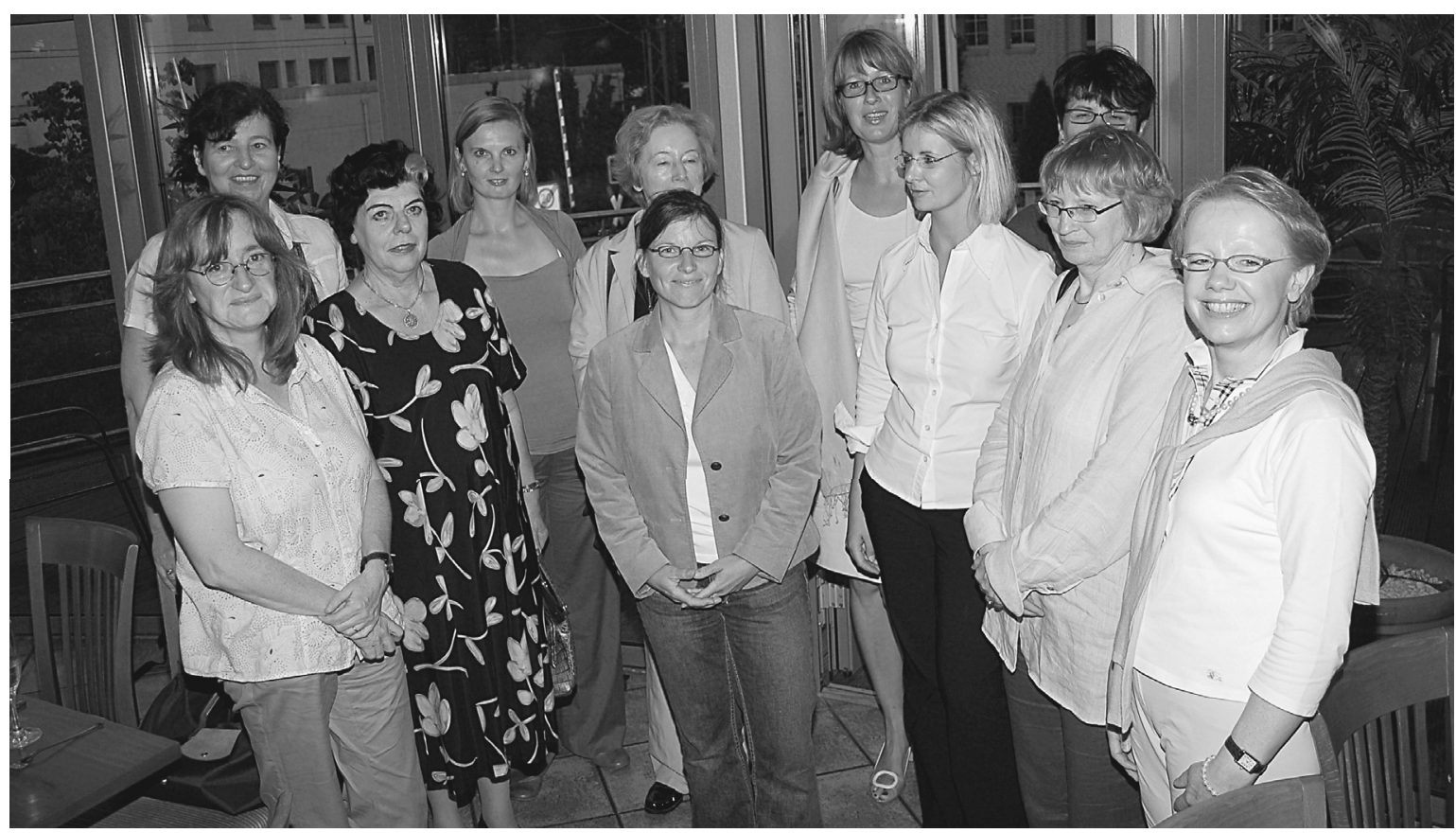

$\triangle$ Sommerempfang der RG Oldenburg am 3. Juli 2008 in Elsfleth mit dem Vortrag der Historikerin und FH-Dozentin Dr. Christine Keitsch, Bremerhaven, „Frauen zur See - weibliche Arbeitskräfte an Bord deutscher Handelsschiffe seit 1945“. V.l.n.r.: Dr. Bettina Graue, Wiss. Mitarbeiterin für ArbeitsR; Birgit Kersten, RAin, vBP; Margretlies Neumann-Nieschlag, RAin und Notarin; Maike Bartlmae, RAin; Dagmar Weber, Vors. Ri am OLG i.R.; Dr. Christine Keitsch, Historikerin, FH-Dozentin; Birgitt Nußbaum, Regierungsrätin; Kerstin Jansen, RAin; Iris Hartlage-Stewes, Vors.Ri am OLG; Hildegard Wurmbach-Swartek, Ri am AG; Brigitte Meyer-Wehage, Ri am AG. 